\title{
A new aspect of an old friend: the beneficial effect of metformin on anti-tumor immunity
}

\author{
KyeongJin Kim ${ }^{1,2}$, Wen-Hao Yang ${ }^{3}$, Youn-Sang Jung ${ }^{4}$ E Jong-ho Cha ${ }^{1,2, *}$ \\ ${ }^{1}$ Department of Biomedical Sciences, College of Medicine, Inha University, Incheon 22212, ${ }^{2}$ Department of Biomedical Science, Program in \\ Biomedical Science and Engineering, Graduate School, Inha University, Incheon 22212, Korea, ${ }^{3}$ Graduate Institute of Biomedical Sciences, \\ China Medical University, Taichung 40402, Taiwan, ${ }^{4}$ Department of Life Science, Chung-Ang University, Seoul 06974, Korea
}

T-cell-based cancer immunotherapies, such as immune checkpoint blockers (ICBs) and chimeric antigen receptor (CAR)-Tcells, have significant anti-tumor effects against certain types of cancer, providing a new paradigm for cancer treatment. However, the activity of tumor infiltrating T-cells (TILs) can be effectively neutralized in the tumor microenvironment (TME) of most solid tumors, rich in various immunosuppressive factors and cells. Therefore, to improve the clinical outcomes of established T-cell-based immunotherapy, adjuvants that can comprehensively relieve multiple immunosuppressive mechanisms of TME are needed. In this regard, recent studies have revealed that metformin has several beneficial effects on anti-tumor immunity. In this mini-review, we understand the immunosuppressive properties of TME and how metformin comprehensively enhances anti-tumor immunity. Finally, we will discuss this old friend's potential as an adjuvant for cancer immunotherapy. [BMB Reports 2020; 53(10): 512-520]

\section{INTRODUCTION}

Metformin is the first-line oral medication for type 2 diabetes (T2D), approved by the FDA in 1994. It has been used for 1.5 million T2D patients worldwide and has been recognized as a safe and well-tolerated drug over the past several decades of clinical experience (1). Interestingly, several case-control studies for T2D patients showed a reduced incidence of various cancer types, suggesting an anti-tumor effect of metformin beyond that against diabetes $(2,3)$. Indeed, several studies have reported an anti-proliferative effect of metformin against various types of cancer by means of different pathways (4). Metformin-activated AMPK inhibits the mammalian target of rapamycin (mTOR)

*Corresponding author. Tel: +82-32-860-9869; Fax: +82-32-885-8302; E-mail: chajongho@inha.ac.kr, cha3843@gmail.com

https://doi.org/10.5483/BMBRep.2020.53.10.149

Received 10 July 2020

Keywords: Adjuvant, Cancer immunotherapy, Cold tumor and tumor microenvironment, Metformin pathway, which regulates protein synthesis, cell proliferation, and cell survival (5). Metformin directly inhibits complex I of the mitochondrial electron-transport chain (ETC), leading to an overall reduction in various intracellular processes that consume ATP (6). Further, metformin treatment induces mitochondriamediated apoptosis by increasing mitochondrion reactive oxygen species (ROS) (7). In addition, metformin can suppress the activation and expression of the signal transducer and activator of transcription 3 (STAT3) important for cancer-cell survival (8, 9). These studies provide mechanisms by which metformin directly inhibits cell growth by targeting the intrinsic pathway inside cancer cells.

Recent studies in the field of immuno-oncology reported the systemic effect of metformin associated with immunity. Interestingly, the anti-tumor effect of metformin is much higher in immunocompetent mouse models than in immunodeficient ones under the same conditions $(10,11)$, implying that the effect of metformin can be primarily mediated by anti-tumor immunity in physiological and clinical conditions. The immunomodulatory activity of metformin was already reported seventy years ago as an anti-viral and anti-malarial effect (12). This finding is supported by several recent findings in which metformin increases CD8 + T-cell activity $(10,13)$.

Since T-cells are the main effector of anti-tumor immunity, T-cell activity has been the final target for most FDA-approved cancer immunotherapies [e.g., ICB (Ipilimumab, Nivolumab, Pembrolizumab, and Atezolizumab), dendritic-cell vaccine (SipuleucelT), and ACT (Axicabtageneciloleucel, and Tisagenlecleucel)] (14). However, since TIL activity is effectively inhibited by protumoral TME, the efficacy of current immunotherapies is limited in most solid tumors. In previous studies on diabetes, cardiovascular disease, and autoimmunity, metformin has been shown to improve the prognosis of each disease by affecting inflammation, hypoxia, angiogenesis, and T-cell activity (3, 15), major components of TME as well. These results imply that the anti-tumor effect of metformin can occur via these TME components. Because these benefits suppress multiple TME components, metformin is worth considering as a potential adjuvant for T-cell-based cancer immunotherapy. 


\section{TUMOR DEVELOPMENT AND ANTI-TUMOR IMMUNITY}

Cancer cells and our immunity are engaged in a fierce battle during tumor development, which occurs in three main stages: initiation, promotion, and progression. During the initiation stage, genomic mutations caused by several carcinogens, such as mutagenic chemicals, radiation, and viruses, can activate oncogenes and inhibit tumor suppressor genes (16). Initiated cells are transformed by the accumulation of critical mutations. When initiated cells are exposed to growth factors, the cells accumulate more mutations with high proliferation during the promotion stages (17). However, most transformed cells are removed by both innate immunity and adaptive immunity [the elimination phase of immunoediting] (18). In innate immunity, cancer cells having an abnormal expression of non-classical major histocompatibility complex (MHC) I are recognized by natural killer (NK) cells, and activated NK cells lyse cancer cells by secreting cytotoxic perforin and granzymes (19). M1 macrophages and dendritic cell (DC)s are recruited by inflammatory chemokines secreted from cancer cells. These antigenpresenting cells (APCs) do not only engulf cancer cells by means of phagocytosis but also support adaptive immunity by presenting tumor antigen to T-cells in the drain lymph node. Finally, educated CD8 + cytotoxic T lymphocytes (CTL) specifically eliminate cancer cells (20). A few cancer cells undergo repeated proliferation and elimination, resulting in their longterm survival without tumor formation [the equilibrium phase of immunoediting] (21). Cancer cells that endured harsh longterm screening obtain mutations to escape from immune surveillance [the escape phase of immunoediting]. Most survived cancer cells down-regulate the level of classic MHC I and the related-antigen processing and presentation machinery (APM), thereby preventing recognition by CD8 + CTL (22). On the other hand, cancer cells increase the level of non-classical MHC I to avoid the threat of NK cells $(23,24)$. After all this, cancer cells that escape from immune surveillance form tumors during the progression stage.

As tumors grow, most solid tumors establish TMEs composed of cellular and non-cellular constituents, including immune cells, fibroblasts, blood vessels, inflammatory signals, hypoxia, and glucose deprivation (25-27). The malignancy of cancer is closely related to the interaction between cancer cells and TME. In particular, pro-tumoral TME, such as hypoxia, chronic inflammation, and immune suppressors [e.g., inhibitory immune checkpoints, M2-like tumor-associated macrophages (TAMs), regulatory T-cells (T regs), and myeloid-derived suppressor cells (MDSCs)], inhibit T-cell surveillance and facilitate metastasis (28).

\section{THE EFFECT OF METFORMIN ON ANTI-TUMOR IMMUNITY}

TME components are entangled in very complex associations, and the malfunction of anti-tumor immunity in TME results from the accumulation of multiple immunosuppressive effects at different stages. Therefore, a comprehensive approach against multiple targets can be effective in improving the efficacy of cancer immunotherapy. The following are TME components targeted by metformin (Fig. 1 and Table 1). We want to understand the effect of metformin in terms of anti-tumor immunity.

\section{The effect of metformin in chronic inflammation}

Inflammation is like a double-edged sword in cancer progression. As an integral part of innate immunity, inflammation plays important roles in removing transformed cells and subsequently presenting cancer antigens for adaptive immunity (29). Nevertheless, chronic inflammation is known to increase the incidence and malignancy in various types of cancer $(30,31)$. Activation of various inflammatory cells, such as macrophages, neutrophils, and mast cells, causes a cytokine storm, including tumor necrosis factor (TNF)- $\alpha$, Interleukin (IL)-1 $\beta$, IL-6, transforming growth factor (TGF)- $\beta$, and ROS (32). Chronic exposure to these inflammatory signals increases the population of M2like TAM in TME (33), and not only induces metastasis by activating angiogenesis and epithelial-mesenchymal transition (EMT) $(26,34)$, but also suppresses T-cell immunity (35). Further, chronic inflammation can differentiate bone-marrow myeloid precursor cells into MDSCs, a major type of immune suppressive cells (36), which deplete T-cells by expressing inhibitory checkpoints and interfering with T-cell trafficking into tumors (37).

Pharmacological and genetic inhibition of these inflammatory factors has reduced tumor growth in animal models, and several control-case studies have shown that using non-steroidal antiinflammatory drugs (NSAIDs) reduces incidence and mortality in various types of cancer (38-40). Recently, an anti-inflammatory effect of metformin has been reported in several different disease models (Fig. 1A and Table 1). Metformin attenuated the induction of multiple sclerosis, a central nervous system (CNS) autoimmune disease. In this study, metformin inhibited the infiltration of monocytes into the CNS by down-regulating the level of chemokines and pro-inflammatory cytokines like IFN- $\gamma$, TNF- $\alpha$, IL-6, and IL-17 (41). Control-case studies on T2D patients indicated that metformin reduces cardiovascular complications $(42,43)$, and related mechanism studies suggested that metformin decreases the level of inflammatory cytokines, including TNF- $\alpha$ and IL- 6 , by inactivating NF- $\mathrm{KB}$ signaling via the AMPK pathway $(44,45)$. Further, metformin also inhibited generation of ROS and IL-1 $\beta$ from LPS-activated macrophages by inhibiting the mitochondrial complex I (46). Consistently, Wang et al. showed that metformin inhibits both tumor growth and angiogenesis by tilting TAM polarization from an M2- to an M1-like phenotype (47). Moreover, Qin et al. reported that metformin has an anti-tumor effect by reducing MDSC accumulation in the TME via the AMPK/DACH1/CXCL1 axis (48). Collectively, metformin has a beneficial effect of alleviating pro-tumoral inflammation, which is expected to prevent cancer malignancy and T-cell exhaustion in the TME. 


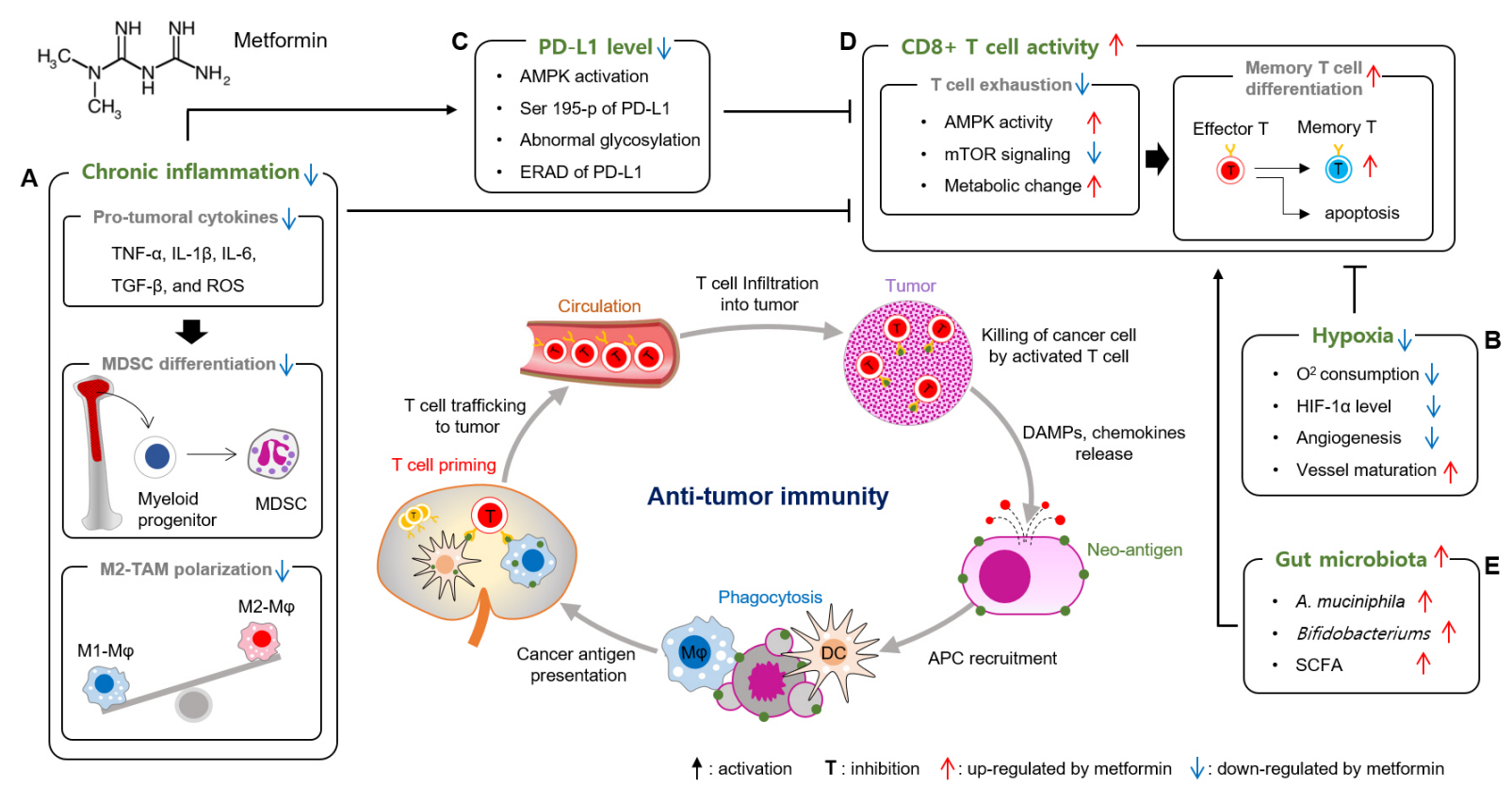

Fig. 1. Several beneficial effects of metformin on anti-tumor immunity. Metformin indirectly increases T-cell activity by negatively regulating (A) chronic inflammation, (B) hypoxia, and (C) PD-L1 levels that inhibit T-cell activity. (D) Metformin directly relieves T-cell exhaustion by means of metabolic reprogramming of TIL and promotes memory T-cell differentiation. (E) Metformin shifts the profile of gut microbiota more favorably to T-cell immunity (TAM) tumor-associated macrophages; (M $\varphi$ ) macrophages; (MDSC) myeloid-derived suppressor cells; (T) T-cell; (DAMPs) Damage-associated molecular patterns; (APC) antigen presenting; (SCFA) short-chain fatty acid.

\section{The effect of metformin in intratumoral hypoxia}

Hypoxia is an important malignant TME component (49). As a tumor grows, cancer cells rapidly consume oxygen. which induces hypoxia in the tumor (50). Cancer cells significantly alter their genetic profiles to overcome the harsh condition and maintain proliferation (51). Hypoxia-inducible factor (HIF-1) accumulated by hypoxia is the major transcription factor that activates genes involved in glucose absorption, glycolysis, and angiogenesis $(51,52)$. Hypoxia and HIF signaling also induce metastasis by increasing expression of EMT-associated genes and by increasing dissemination of cancer cells by means of angiogenesis (53). Furthermore, hypoxia and HIF signaling help cancer cells escape from immune surveillance. Hypoxia and HIF signaling are known to increase the population of immunosuppressive cells, such as MDSCs, M2-like TAM, and Treg, in the tumor $(54,55)$. In addition, hypoxia may interfere with adaptive immunity by inhibiting the stimulatory capacity of DC to activate T-cells (56). Hypoxia also limits the number of TILs by reducing proliferation and viability in the TME (57). Consistently, hypoxia increases the level of PD-L1, a major inhibitory immune checkpoint molecule that induces T-cell exhaustion in the TME.

A recent study reported the anti-hypoxic effect of metformin (Fig. 1B and Table 1). In this study, metformin treatment reduced a hypoxic probe-positive area, which was accompanied by a reduced level of HIF-1 $\alpha$ and pro-angiogenic factors (58). Con- sistently, metformin suppresses accumulation of HIF- $1 \alpha$ by hypoxia in hepatocellular carcinoma (59) and oral squamous-cell carcinoma (60). Importantly, Scharping et al. reported that metformin can relieve intratumoral hypoxia by reducing oxygen consumption, resulting in improving T-cell immunity in the TME. Consequently, metformin had a significant synergetic anti-tumor effect with ICB targeting PD-1 (61). Such evidence suggests that metformin treatment can improve T-cell immunity by alleviating intratumoral hypoxia.

\section{The effect of metformin in the expression of PD-L1}

Programmed death-ligand 1 (PD-L1) is a main immune checkpoint molecule that negatively regulates T-cell activity. In various cancer types, such as renal-cell carcinoma (RCC) breast cancer, colorectal cancer, gastric cancer, non-small-cell lung cancer (NSCLC), papillary thyroid, and testicular cancers (62, 63), a high level of PD-L1 expression is observed, which is associated with poor prognosis (63-65). The binding of PD-L1 with programmed cell death protein 1 (PD-1) receptor on activated CD8 + CTL inhibits a T-cell receptor (TCR) signaling cascade and suppresses the activity of CTLs $(66,67)$. Therefore, there have been active attempts to restore CTL activity by blocking PD-L1/PD-1 signaling. FDA approved-ICBs, such as nivolumab, pembrolizumab, and atezolizumab, target PD-1 or PD-L1 (14).

Recently, our group reported that metformin can increase 
Table 1. The effect of metformin and its downstream factors on TME components

\begin{tabular}{|c|c|c|c|c|}
\hline TME components & $\begin{array}{l}\text { Key regulator / } \\
\text { region }\end{array}$ & Regulatory mechanism & Disease & References \\
\hline \multirow[t]{5}{*}{$\begin{array}{l}\text { Chronic } \\
\text { inflammation }\end{array}$} & $\begin{array}{l}\text { IFN- } \gamma, \text { TNF- } \alpha, \text { IL-6, } \\
\text { and IL-17 }\end{array}$ & $\begin{array}{l}\text { Metformin down-regulates the level of chemokines and } \\
\text { pro-inflammatory cytokines. }\end{array}$ & Multiple sclerosis & (41) \\
\hline & TNF- $\alpha$ and IL-6 & $\begin{array}{l}\text { Metformin decreases the level of inflammatory cytokines } \\
\text { by suppressing NF- } \mathrm{kB} \text { signaling. }\end{array}$ & $\begin{array}{l}\text { T2D, cardiovascular } \\
\text { complications }\end{array}$ & $\begin{array}{l}(42,43) \\
(44,45)\end{array}$ \\
\hline & ROS and IL-1 $\beta$ & $\begin{array}{l}\text { Metformin decreases the level of inflammatory cytokines } \\
\text { from LPS-activated macrophages by means of inhibition } \\
\text { of mitochondrial complex I. }\end{array}$ & Inflammation & (46) \\
\hline & TAM polarization & $\begin{array}{l}\text { Metformin inhibit tumor growth by promoting M2-TAM } \\
\text { polarization }\end{array}$ & Cancer & (47) \\
\hline & MDSC chemotaxis & $\begin{array}{l}\text { Metformin has anti-tumor effect by reducing MDSC } \\
\text { accumulation in the TME via AMPK/DACH1/CXCL1 axis. }\end{array}$ & Cancer & (48) \\
\hline \multirow[t]{3}{*}{ Hypoxia } & Hypoxia & Metformin reduces intratumoral hypoxia. & Cancer & (58) \\
\hline & HIF-1 $\alpha$ & Metformin suppresses accumulation of HIF- $1 \alpha$. & Cancer & $(59,60)$ \\
\hline & $\begin{array}{l}\text { Oxygen } \\
\text { consumption }\end{array}$ & $\begin{array}{l}\text { Metformin relieves intratumoral hypoxia, resulting in } \\
\text { improving T-cell immunity in the TME. }\end{array}$ & Cancer & (61) \\
\hline \multirow[t]{3}{*}{ PD-L1 expression } & PD-L1 & $\begin{array}{l}\text { Metformin-activated AMPK induces ERAD of PD-L1, } \\
\text { resulting in enhanced CD8 + TIL activity. }\end{array}$ & Cancer & (11) \\
\hline & PD-L1 & $\begin{array}{l}\text { Metformin improves cytotoxicity of CD8 + T-cell by } \\
\text { reducing membrane-bound PD-L1 level. }\end{array}$ & Cancer & (68) \\
\hline & PD-L1 & $\begin{array}{l}\text { Metformin treatment reverses PD-L1 level, which } \\
\text { sensitizes PARPi-resistant cells to CTL. }\end{array}$ & Cancer & (69) \\
\hline \multirow{5}{*}{$\begin{array}{l}\text { Metabolic } \\
\text { reprogramming of } \\
\text { T-cell }\end{array}$} & AMPK & $\begin{array}{l}\text { Metformin does not only increase the multi-functionality of } \\
\mathrm{CD} 8^{+} \mathrm{CTL} \text { but also improve long-term memory immunity. }\end{array}$ & Cancer & (10) \\
\hline & $\begin{array}{l}\text { Oxidative } \\
\text { metabolism }\end{array}$ & $\begin{array}{l}\text { AMPK maintain consistent activity of CTL under glucose } \\
\text { depletion. }\end{array}$ & Cancer & (76) \\
\hline & $\begin{array}{l}\text { Protein } \\
\text { phosphatases }\end{array}$ & $\begin{array}{l}\text { Genetic ablation of AMPK } \alpha 1 \text { in T-cell cause apoptosis of } \\
\text { CD8 + CTL. }\end{array}$ & Cancer & (77) \\
\hline & mTORC1 & $\begin{array}{l}\text { TSC2 KO mice generate highly glycolytic and potent } \\
\text { effector CTL. }\end{array}$ & Cancer & (78) \\
\hline & mTOR & $\begin{array}{l}\text { Rapamycin treatment increases the population of CD8 + } \\
\text { memory T-cells. }\end{array}$ & Virus infection & (82) \\
\hline
\end{tabular}

anti-tumor immunity by improving CD8 + TIL activity (Fig. 1C and Table 1) (11). As the underlining mechanism, metforminactivated AMPK directly phosphorylates at Serine 195 of PD$\mathrm{L} 1$, and this phosphorylation induces abnormal glycosylation of PD-L1. Eventually, abnormal PD-L1 is degraded by means of the endoplasmic-reticulum-associated protein degradation (ERAD) pathway, which recovers CD8 + CTL activity. Furthermore, metformin-treated breast cancer patients' data and animal work strongly support that a combination of metformin with a non-PD-1/PD-L1 targeting ICB can be effective in treating patients with PD-L1-expressing tumors. Similar to these results, Verdure et al. mentioned that metformin improves cytotoxicity of CD8 + T-cells by reducing the membrane-bound PD-L1 level increased by IFN- $\gamma$ treatment (68). Consistently, Han et al. showed that poly ADP ribose polymerase inhibitor (PARPi)resistant cells up-regulate PD-L1 expression, and metformin treatment reverses the PD-L1 level, which sensitizes PARPi-resistant cells to CTL (69). These studies all suggest that metformin can increase T-cell immunity by reducing PD-L1 level in the TME.

\section{The effect of metformin in metabolic reprogramming of T-cells}

In adaptive immunity, effector CD8 + CTLs educated by phagocytic APCs in the drain lymph nodes can specifically recognize and kill tumor cells (70). However, effector CTLs undergo metabolic exhaustion in TME, which causes their malfunction and apoptosis (71). The cancer cell relies on ineffective aerobic glycolysis as the main source of ATP, not oxidative phosphorylation, and fills the need by actively absorbing glucose (72). An unusual metabolic property called the 'Warburg effect' has an advantage for cancer cells in survival under hypoxia. Interestingly, the metabolism of effector CTL is converted to aerobic glycolysis after binding with a cancer antigen in the tumor (73). This metabolic similarity encourages glucoseuptake competition between cancer cells and CTL, leading to metabolic exhaustion of effector CD8 + CTL (74). In this regard, the metabolic reprogramming of exhausted T-cells can be a therapeutic target to increase anti-tumor immunity.

Since AMPK and mTOR, downstream factors of metformin, 
are the main regulators in energy sensing and mitochondrial function, metformin may play on the metabolic reprogramming of exhausted T-cells (Fig. 1D and Table 1) (75). Indeed, metformin treatment has been demonstrated to increase the number of CD8 + CTL and prevent their exhaustion in the tumor (10, 11). AMPK is reported to maintain consistent activity of CTL by activating oxidative metabolism under glucose depletion (76). Rao et al. also showed that genetic ablation of AMPK $\alpha 1$ in T-cells cause apoptosis of CD8 + CTL during in vitro activation and in vivo tumor development, and promote tumor growth in an immune-competent mouse model (77). Consistently, when tuberous sclerosis complex 2 (TSC2), an mTORC1 negative regulator, is genetically ablated, the mice showed the generation of highly glycolytic and potent effector CTL (78).

Most CD8 + T-cells that have completed their mission are removed by means of apoptosis, and some of them differentiate into CD8 + memory T-cells, which respond faster and more effectively to the same enemy, preventing recurrence (79). This transition to CD8 + memory T-cells also requires metabolic reprogramming (80). Interestingly, Elikawa et al. showed that metformin not only increases the multi-functionality of CD8+ CTL but also improves long-term memory immunity (10). In this study, metformin treatment increased the effector memory T-cell/central memory T-cell (TEMTCM) ratio. Indeed, the AMPKmTOR pathway is known to regulate memory CD8 + T-cell differentiation. Cantrell et al showed that AMPK $\alpha 1$-deficient Tcells have a defect in generation of CD8 + memory T-cells (81). Consistent with this result, mTOR inhibition with rapamycin increased the population of CD8 + memory T-cells in a virusinfected mice and primate model (82). Overall, metformin probably increases anti-tumor efficacy of CTL and its in vivo persistence by means of metabolic reprogramming via the AMPK/ mTOR pathway.

\section{PERSPECTIVES AND FUTURE DIRECTIONS}

Abnormal gut microbiota profiles have emerged in a variety of diseases related to immune disorder, such as inflammatory bowel disease, rheumatoid arthritis, myocardial metabolic disease, CNS autoimmune disease, and cancer $(83,84)$. Symptoms of such diseases have been improved by means of microbial modulation by dietary therapy or direct transplantation of beneficial microbes (85), suggesting that the balance between the immune system and the symbiotic microbiota is very important for maintaining our immunity. The following studies suggest that gut microbiota may be an important mediator of metformin which positively affects anti-tumor immunity.

Recently, three different groups reported at similar times that distinct gut microbiota profiles are observed between ICB responders and non-reponders, and that the therapeutic efficacy of ICB is greatly affected by the gut microbiota (86-88). The fecal microbial transplant (FMT) model showed that the efficacy of ICB is much higher in mice transplanted from IBC responders than in those from non-responders, and FMT from ICB responders highly improved T-cell immunity. In addition, microbes beneficial for ICB immunotherapy were identified as (1) Faecalibacterium prausnitzii (86), (2) Bifidobacterium longum (87), and (3) Akkermansia muciniphila (88).

Cuesta-Zuluaga et al. demonstrated the relevance of T2D, metformin, and gut microbiota (Fig. 1E and Table 1) (89). Interestingly, metformin shifted the gut microbiota profile of T2D patients, and in particular increased A. muciniphila and several

Table 2. Current clinical trials of metformin combined with ICB

\begin{tabular}{|c|c|c|c|c|c|}
\hline Title (NCT No.) & Schedule & Disease & Drug & $\begin{array}{c}\text { Sponsor } \\
\text { (Collaborator) }\end{array}$ & Phases \\
\hline $\begin{array}{l}\text { Nivolumab and Metformin Hydrochloride in } \\
\text { Treating Patients With } \\
\text { Stage III-IV Non-small Cell Lung Cancer } \\
\text { That Cannot Be Removed by Surgery } \\
\text { (NCT03048500) }\end{array}$ & $\begin{array}{l}\text { Start : Jun. } 2017 \\
\text { End : Feb. } 2021\end{array}$ & NSCLC & $\begin{array}{l}\text { Metformin } \\
\text { Nivolumab }\end{array}$ & $\begin{array}{l}\text { Northwestern } \\
\text { University } \\
\text { (BMS, NCl) }\end{array}$ & Phase 2 \\
\hline $\begin{array}{l}\text { Nivolumab and Metformin in Patients With } \\
\text { Treatment Refractory MSS Colorectal Cancer } \\
\text { (NCT03800602) }\end{array}$ & $\begin{array}{l}\text { Start: Jan. } 2019 \\
\text { End : Jan. } 2023\end{array}$ & $\begin{array}{l}\text { Colorectal } \\
\text { cancer }\end{array}$ & $\begin{array}{l}\text { Metformin } \\
\text { Nivolumab }\end{array}$ & $\begin{array}{l}\text { Emory } \\
\text { University } \\
\text { (BMS) }\end{array}$ & Phase 2 \\
\hline $\begin{array}{l}\text { Combining Pembrolizumab and Metformin in } \\
\text { Metastatic Head and Neck Cancer Patients } \\
\text { (NCT04414540) }\end{array}$ & $\begin{array}{l}\text { Start: Jul. } 2020 \\
\text { End : Feb. } 2024\end{array}$ & HNSCC & $\begin{array}{l}\text { Metformin } \\
\text { Pembrolizumab }\end{array}$ & $\begin{array}{l}\text { UC Health } \\
\text { (American } \\
\text { Cancer } \\
\text { Society) }\end{array}$ & Phase 2 \\
\hline $\begin{array}{l}\text { Anti-PD-1 mAb Plus Metabolic Modulator in } \\
\text { Solid Tumor Malignancies } \\
\text { (NCT04114136) }\end{array}$ & $\begin{array}{l}\text { Start: May } 2020 \\
\text { End : Nov. } 2023\end{array}$ & $\begin{array}{l}\text { Melanoma } \\
\text { RCC } \\
\text { NSCLC } \\
\text { HCC HNSCC }\end{array}$ & $\begin{array}{l}\text { Metformin } \\
\text { Pembrolizumab } \\
\text { Nivolumab }\end{array}$ & $\begin{array}{l}\text { University of } \\
\text { Pittsburgh }\end{array}$ & Phase 2 \\
\hline $\begin{array}{l}\text { A Trial of Pembrolizumab and MetforminVersus } \\
\text { Pembrolizumab Alone in Advanced Melanoma } \\
\text { (NCT03311308) }\end{array}$ & $\begin{array}{l}\text { Start: Dec. } 2017 \\
\text { End : Dec. } 2028\end{array}$ & Melanoma & $\begin{array}{l}\text { Metformin } \\
\text { Pembrolizumab }\end{array}$ & $\begin{array}{l}\text { University of } \\
\text { Pittsburgh } \\
\text { (Merck) }\end{array}$ & Phase 1 \\
\hline
\end{tabular}


Bifidobacterium species. As mentioned, A. muciniphila and Bifidobacterium are species identified as microbes beneficial for ICB immunotherapy $(87,88)$. Further, A. muciniphila and Bifidobacterium species are known to produce short-chain fatty acids (SCFA), like acetate, propionate, and butyrate, which have immune-modulatory and anti-inflammatory effects (90, 91). Such evidence strongly supports that metformin could affect anti-tumor immunity in a systematic manner via gut microbiota. However, it is largely undefined how metformin can shift a gut microbiota profile to be favorable to anti-tumor immunity and what is the link between metformin-increased germ species and anti-tumor immunity. To address these issues, future studies are needed, which are expected to greatly increase the usefulness of metformin and provide new insights and therapeutic targets for cancer immunity.

\section{CONCLUDING REMARKS}

Most of the current cancer immunotherapy targets TIL and works by maintaining the activity of TIL in TME. In order to ensure their effectiveness, anti-tumor immune processes, including APCs infiltration, cancer antigen presentation, T-cell priming, and TIL activity maintenance, must be adequately achieved (92). Indeed, "hot" tumors that achieve these prerequisites respond well to cancer immunotherapy, but "cold" tumors that do not meet the prerequisites have a poor response to immunotherapy (93). If cold tumors can turn into hot ones, we could greatly improve the efficacy of current cancer immunotherapy, as well as expand the beneficiaries.

In this favorable conversion, the problem is that immunosuppressive TME in cold tumors inhibits multiple targets at different stages of anti-tumor immunity (94). Therefore, it would be difficult to expect an effective conversion with a single factor or path-adjusting approach. Although the choice of inhibitor cocktail can be considered to target multiple immunosuppressive factors, it would probably cause excessive side effects, such as accumulated toxicity. To support the conversion of cold tumors, the repositioning of previously well-tolerated drugs that have a multi-immunomodulatory effect would be a more effective and safer approach.

As summarized in this mini-review, metformin's safety and tolerability have been proven by decades of clinical experience. In addition, this drug has multiple beneficial effects on antitumor immunity, such as by havinging anti-inflammatory and anti-hypoxic effects, increasing T-cell activity, and acting favorably on the gut microbiota (Fig. 1 and Table 2). Moreover, control-case studies showed that metformin reduces the incidence of various types of cancer, and the positive effect of metformin on anti-tumor immunity has been consistently observed by means of several animal models. These findings strongly suggest that metformin has a high potential to be an adjuvant to comprehensively overwhelm immunosuppressive TMEs by supporting the stable conversion of cold tumors.

In current clinical trials that reflect this possibility, metfor- min is being co-administered with ICB targeting PD-L1/PD-1 (nivolumab and pembrolizumab) in patients with advanced melanoma, colorectal cancer, hepatocellular carcinoma (HCC), head and neck squamous-cell carcinoma (HNSCC), NSCLC, and RCC (Table 2). In anticipation of the old friend's reevaluation, let's pay attention to the upcoming results.

\section{ACKNOWLEDGEMENTS}

This work was supported in part by the following: The National Research Foundation of Korea (NRF) grant funded by the Korea government Ministry of Science and ICT (MSIT) (2020R1C1C1 005631 to J.-H. Cha and 2020R1C1C1004015 to K. Kim), INHA UNIVERSITY Research Grant [to K. Kim and J.-H. Cha], Ying Tsai Young Scholar Award (CMU108-YTY-04), the Ministry of Science and Technology (MOST; 109-2314-B-039-054) [to W.-H. Yang], and CHUNG-ANG UNIVERSITY Grant [to Y.-S. Jung].

\section{CONFLICTS OF INTEREST}

The authors have no conflicting interest.

\section{REFERENCES}

1. Irons BK and Minze MG (2014) Drug treatment of type 2 diabetes mellitus in patients for whom metformin is contraindicated. Diabetes Metab Syndr Obes 7, 15-24

2. Evans JM, Donnelly LA, Emslie-Smith AM, Alessi DR and Morris AD (2005) Metformin and reduced risk of cancer in diabetic patients. BMJ 330, 1304-1305

3. Viollet B, Guigas B, Sanz Garcia N, Leclerc J, Foretz M and Andreelli F (2012) Cellular and molecular mechanisms of metformin: an overview. Clin Sci (Lond) 122, 253-270

4. Aljofan M and Riethmacher D (2019) Anticancer activity of metformin: a systematic review of the literature. Future Sci OA 5, FSO410

5. Dowling RJ, Zakikhani M, Fantus IG, Pollak $M$ and Sonenberg N (2007) Metformin inhibits mammalian target of rapamycin-dependent translation initiation in breast cancer cells. Cancer Res 67, 10804-10812

6. Andrzejewski S, Siegel PM and St-Pierre J (2018) Metabolic Profiles Associated With Metformin Efficacy in Cancer. Front Endocrinol (Lausanne) 9, 372

7. Tseng HW, Li SC and Tsai KW (2019) Metformin Treatment Suppresses Melanoma Cell Growth and Motility Through Modulation of microRNA Expression. Cancers (Basel) 11, 209

8. Deng XS, Wang S, Deng A et al (2012) Metformin targets Stat3 to inhibit cell growth and induce apoptosis in triple-negative breast cancers. Cell Cycle 11, 367-376

9. Feng Y, Ke C, Tang Q et al (2014) Metformin promotes autophagy and apoptosis in esophageal squamous cell carcinoma by downregulating Stat 3 signaling. Cell Death Dis 5, e1088

10. Eikawa S, Nishida M, Mizukami S, Yamazaki C, Nakayama $\mathrm{E}$ and Udono $\mathrm{H}$ (2015) Immune-mediated antitumor effect by type 2 diabetes drug, metformin. Proc Natl Acad Sci U 
S A 112, 1809-1814

11. Cha JH, Yang WH, Xia $W$ et al (2018) Metformin Promotes Antitumor Immunity via Endoplasmic-ReticulumAssociated Degradation of PD-L1. Mol Cell 71, 606-620 e607

12. Garcia EY (1950) Flumamine, a new synthetic analgesic and anti-flu drug. J Philipp Med Assoc 26, 287-293

13. Zhang Z, Li F, Tian Y et al (2020) Metformin Enhances the Antitumor Activity of CD8(+) T Lymphocytes via the AMPKmiR-107-Eomes-PD-1 Pathway. J Immunol 204, 2575-2588

14. Cha JH, Chan LC, Song MS and Hung MC (2019) New Approaches on Cancer Immunotherapy. Cold Spring Harb Perspect Med 10, a036863

15. Del Barco S, Vazquez-Martin A, Cufi S et al (2011) Metformin: multi-faceted protection against cancer. Oncotarget 2, 896-917

16. Basu AK (2018) DNA Damage, Mutagenesis and Cancer. Int J Mol Sci 19, 970

17. Hyndman IJ (2016) Review: the Contribution of both Nature and Nurture to Carcinogenesis and Progression in Solid Tumours. Cancer Microenviron 9, 63-69

18. Mittal D, Gubin MM, Schreiber RD and Smyth MJ (2014) New insights into cancer immunoediting and its three component phases-elimination, equilibrium and escape. Curr Opin Immunol 27, 16-25

19. Paul S and Lal G (2017) The Molecular Mechanism of Natural Killer Cells Function and Its Importance in Cancer Immunotherapy. Front Immunol 8, 1124

20. Reeves E and James E (2017) Antigen processing and immune regulation in the response to tumours. Immunology $150,16-24$

21. Kim R, Emi M and Tanabe K (2007) Cancer immunoediting from immune surveillance to immune escape. Immunology $121,1-14$

22. de Charette M, Marabelle A and Houot R (2016) Turning tumour cells into antigen presenting cells: The next step to improve cancer immunotherapy? Eur J Cancer 68, 134-147

23. Halenius A, Gerke C and Hengel H (2015) Classical and non-classical MHC I molecule manipulation by human cytomegalovirus: so many targets-but how many arrows in the quiver? Cell Mol Immunol 12, 139-153

24. Kochan G, Escors D, Breckpot K and Guerrero-Setas D (2013) Role of non-classical MHC class I molecules in cancer immunosuppression. Oncoimmunology 2, e26491

25. Balkwill FR, Capasso M and Hagemann T (2012) The tumor microenvironment at a glance. J Cell Sci 125, 55915596

26. Gajewski TF, Schreiber H and Fu YX (2013) Innate and adaptive immune cells in the tumor microenvironment. Nat Immunol 14, 1014-1022

27. Wang M, Zhao J, Zhang L et al (2017) Role of tumor microenvironment in tumorigenesis. J Cancer 8, 761-773

28. Quail DF and Joyce JA (2013) Microenvironmental regulation of tumor progression and metastasis. Nat Med 19, 1423-1437

29. Kambayashi T and Laufer TM (2014) Atypical MHC class II-expressing antigen-presenting cells: can anything replace a dendritic cell? Nat Rev Immunol 14, 719-730

30. Hagemann T, Balkwill F and Lawrence T (2007) Inflammation and cancer: a double-edged sword. Cancer Cell
12, 300-301

31. Zitvogel L, Pietrocola F and Kroemer G (2017) Nutrition, inflammation and cancer. Nat Immunol 18, 843-850

32. Dranoff G (2004) Cytokines in cancer pathogenesis and cancer therapy. Nat Rev Cancer 4, 11-22

33. Poh AR and Ernst M (2018) Targeting Macrophages in Cancer: From Bench to Bedside. Front Oncol 8, 49

34. Landskron $G$, De la Fuente $M$, Thuwajit $P$, Thuwajit $C$ and Hermoso MA (2014) Chronic inflammation and cytokines in the tumor microenvironment. J Immunol Res 2014, 149185

35. D'Elia RV, Harrison K, Oyston PC, Lukaszewski RA and Clark GC (2013) Targeting the "cytokine storm" for therapeutic benefit. Clin Vaccine Immunol 20, 319-327

36. Kumar V, Patel S, Tcyganov E and Gabrilovich DI (2016) The Nature of Myeloid-Derived Suppressor Cells in the Tumor Microenvironment. Trends Immunol 37, 208-220

37. Hanson EM, Clements VK, Sinha P, Ilkovitch D and Ostrand-Rosenberg S (2009) Myeloid-derived suppressor cells down-regulate L-selectin expression on CD4 + and CD8 + T cells. J Immunol 183, 937-944

38. Crusz SM and Balkwill FR (2015) Inflammation and cancer: advances and new agents. Nat Rev Clin Oncol 12, 584-596

39. Brasky TM, Potter JD, Kristal AR et al (2012) Non-steroidal anti-inflammatory drugs and cancer incidence by sex in the VITamins And Lifestyle (VITAL) cohort. Cancer Causes Control 23, 431-444

40. Liu Y, Chen JQ, Xie L et al (2014) Effect of aspirin and other non-steroidal anti-inflammatory drugs on prostate cancer incidence and mortality: a systematic review and meta-analysis. BMC Med 12, 55

41. Nath N, Khan M, Paintlia MK, Singh I, Hoda MN and Giri S (2009) Metformin attenuated the autoimmune disease of the central nervous system in animal models of multiple sclerosis. J Immunol 182, 8005-8014

42. Triggle CR and Ding H (2014) Cardiovascular impact of drugs used in the treatment of diabetes. Ther Adv Chronic Dis 5, 245-268

43. Lund SS, Tarnow L, Stehouwer CD et al (2008) Impact of metformin versus repaglinide on non-glycaemic cardiovascular risk markers related to inflammation and endothelial dysfunction in non-obese patients with type 2 diabetes. Eur J Endocrinol 158, 631-641

44. Huang NL, Chiang SH, Hsueh CH, Liang YJ, Chen YJ and Lai LP (2009) Metformin inhibits TNF-alpha-induced IkappaB kinase phosphorylation, IkappaB-alpha degradation and IL-6 production in endothelial cells through PI3K-dependent AMPK phosphorylation. Int J Cardiol 134, 169-175

45. Ersoy C, Kiyici S, Budak F et al (2008) The effect of metformin treatment on VEGF and PAI-1 levels in obese type 2 diabetic patients. Diabetes Res Clin Pract 81, 56-60

46. Kelly B, Tannahill GM, Murphy MP and O'Neill LA (2015) Metformin Inhibits the Production of Reactive Oxygen Species from NADH:Ubiquinone Oxidoreductase to Limit Induction of Interleukin-1beta (IL-1beta) and Boosts Interleukin-10 (IL-10) in Lipopolysaccharide (LPS)-activated Macrophages. J Biol Chem 290, 20348-20359

47. Wang JC, Sun X, Ma Q et al (2018) Metformin's antitumour and anti-angiogenic activities are mediated by 
skewing macrophage polarization. J Cell Mol Med 22, 38253836

48. Qin G, Lian J, Huang L et al (2018) Metformin blocks myeloid-derived suppressor cell accumulation through AMPK-DACH1-CXCL1 axis. Oncoimmunology 7, e1442167

49. Semenza GL (2016) The hypoxic tumor microenvironment: A driving force for breast cancer progression. Biochim Biophys Acta 1863, 382-391

50. Brown JM (1999) The hypoxic cell: a target for selective cancer therapy--eighteenth Bruce F. Cain Memorial Award lecture. Cancer Res 59, 5863-5870

51. Eales KL, Hollinshead KE and Tennant DA (2016) Hypoxia and metabolic adaptation of cancer cells. Oncogenesis 5, e190

52. Weidemann A and Johnson RS (2008) Biology of HIF1alpha. Cell Death Differ 15, 621-627

53. Subarsky P and Hill RP (2003) The hypoxic tumour microenvironment and metastatic progression. Clin Exp Metastasis 20, 237-250

54. Noman MZ, Messai Y, Carre T et al (2011) Microenvironmental hypoxia orchestrating the cell stroma cross talk, tumor progression and antitumor response. Crit Rev Immunol 31, 357-377

55. Clambey ET, McNamee EN, Westrich JA et al (2012) Hypoxia-inducible factor-1 alpha-dependent induction of FoxP3 drives regulatory T-cell abundance and function during inflammatory hypoxia of the mucosa. Proc Natl Acad Sci U S A 109, E2784-2793

56. Mancino A, Schioppa T, Larghi $P$ et al (2008) Divergent effects of hypoxia on dendritic cell functions. Blood 112, 3723-3734

57. Vuillefroy de Silly R, Dietrich PY and Walker PR (2016) Hypoxia and antitumor CD8 + T cells: An incompatible alliance? Oncoimmunology 5, e1232236

58. Wang JC, Li GY, Li PP et al (2017) Suppression of hypoxia-induced excessive angiogenesis by metformin via elevating tumor blood perfusion. Oncotarget 8, 73892-73904

59. Zhou X, Chen J, Yi G et al (2016) Metformin suppresses hypoxia-induced stabilization of HIF-1alpha through reprogramming of oxygen metabolism in hepatocellular carcinoma. Oncotarget 7, 873-884

60. Guimaraes TA, Farias LC, Santos ES et al (2016) Metformin increases PDH and suppresses HIF-1alpha under hypoxic conditions and induces cell death in oral squamous cell carcinoma. Oncotarget 7, 55057-55068

61. Scharping NE, Menk AV, Whetstone RD, Zeng $X$ and Delgoffe GM (2017) Efficacy of PD-1 Blockade Is Potentiated by Metformin-Induced Reduction of Tumor Hypoxia. Cancer Immunol Res 5, 9-16

62. Thompson RH, Gillett MD, Cheville JC et al (2004) Costimulatory $\mathrm{B} 7-\mathrm{H} 1$ in renal cell carcinoma patients: Indicator of tumor aggressiveness and potential therapeutic target. Proc Natl Acad Sci U S A 101, 17174-17179

63. Zhang M, Li G, Wang Y et al (2017) PD-L1 expression in lung cancer and its correlation with driver mutations: a meta-analysis. Sci Rep 7, 10255

64. Brody R, Zhang Y, Ballas M et al (2017) PD-L1 expression in advanced NSCLC: Insights into risk stratification and treatment selection from a systematic literature review. Lung Cancer 112, 200-215
65. Li J, Wang P and Xu Y (2017) Prognostic value of programmed cell death ligand 1 expression in patients with head and neck cancer: A systematic review and metaanalysis. PLoS One 12, e0179536

66. Schildberg FA, Klein SR, Freeman GJ and Sharpe AH (2016) Coinhibitory Pathways in the B7-CD28 Ligand-Receptor Family. Immunity 44, 955-972

67. Pardoll DM (2012) The blockade of immune checkpoints in cancer immunotherapy. Nat Rev Cancer 12, 252-264

68. Verdura S, Cuyas E, Martin-Castillo B and Menendez JA (2019) Metformin as an archetype immuno-metabolic adjuvant for cancer immunotherapy. Oncoimmunology 8, e1633235

69. Han Y, Li CW, Hsu JM et al (2019) Metformin reverses PARP inhibitors-induced epithelial-mesenchymal transition and PD-L1 upregulation in triple-negative breast cancer. Am J Cancer Res 9, 800-815

70. Garner H and de Visser KE (2020) Immune crosstalk in cancer progression and metastatic spread: a complex conversation. Nat Rev Immunol 20, 483-497

71. Voss K, Larsen SE and Snow AL (2017) Metabolic reprogramming and apoptosis sensitivity: Defining the contours of a T cell response. Cancer Lett 408, 190-196

72. Burns JS and Manda G (2017) Metabolic Pathways of the Warburg Effect in Health and Disease: Perspectives of Choice, Chain or Chance. Int J Mol Sci 18, 2755

73. Almeida L, Lochner M, Berod L and Sparwasser T (2016) Metabolic pathways in T cell activation and lineage differentiation. Semin Immunol 28, 514-524

74. Afonso J, Santos LL, Longatto-Filho A and Baltazar F (2020) Competitive glucose metabolism as a target to boost bladder cancer immunotherapy. Nat Rev Urol 17, 77-106

75. Garza-Lombo C, Schroder A, Reyes-Reyes EM and Franco $R$ (2018) mTOR/AMPK signaling in the brain: Cell metabolism, proteostasis and survival. Curr Opin Toxicol $8,102-110$

76. Blagih J, Coulombe F, Vincent EE et al (2015) The energy sensor AMPK regulates $T$ cell metabolic adaptation and effector responses in vivo. Immunity 42, 41-54

77. Rao E, Zhang Y, Zhu G et al (2015) Deficiency of AMPK in CD8 + T cells suppresses their anti-tumor function by inducing protein phosphatase-mediated cell death. Oncotarget 6, 7944-7958

78. Pollizzi KN, Patel $\mathrm{CH}$, Sun IH et al (2015) mTORC1 and mTORC2 selectively regulate CD8(+) T cell differentiation. J Clin Invest 125, 2090-2108

79. Pennock ND, White JT, Cross EW, Cheney EE, Tamburini BA and Kedl RM (2013) T cell responses: naive to memory and everything in between. Adv Physiol Educ 37, 273-283

80. van der Windt GJ and Pearce EL (2012) Metabolic switching and fuel choice during T-cell differentiation and memory development. Immunol Rev 249, 27-42

81. Rolf J, Zarrouk M, Finlay DK, Foretz $M$, Viollet B and Cantrell DA (2013) AMPKalpha1: a glucose sensor that controls CD8 T-cell memory. Eur J Immunol 43, 889-896

82. Araki K, Turner AP, Shaffer VO et al (2009) mTOR regulates memory CD8 T-cell differentiation. Nature 460, 108-112

83. Durack J and Lynch SV (2019) The gut microbiome: 
Relationships with disease and opportunities for therapy. J Exp Med 216, 20-40

84. Xu H, Liu M, Cao J et al (2019) The Dynamic Interplay between the Gut Microbiota and Autoimmune Diseases. J Immunol Res 2019, 7546047

85. Balakrishnan B and Taneja V (2018) Microbial modulation of the gut microbiome for treating autoimmune diseases. Expert Rev Gastroenterol Hepatol 12, 985-996

86. Gopalakrishnan V, Spencer CN, Nezi L et al (2018) Gut microbiome modulates response to anti-PD-1 immunotherapy in melanoma patients. Science 359, 97-103

87. Matson V, Fessler J, Bao R et al (2018) The commensal microbiome is associated with anti-PD-1 efficacy in metastatic melanoma patients. Science 359, 104-108

88. Routy B, Le Chatelier E, Derosa L et al (2018) Gut microbiome influences efficacy of PD-1-based immunotherapy against epithelial tumors. Science 359, 91-97

89. de la Cuesta-Zuluaga J, Mueller NT, Corrales-Agudelo V et al (2017) Metformin Is Associated With Higher Relative
Abundance of Mucin-Degrading Akkermansia muciniphila and Several Short-Chain Fatty Acid-Producing Microbiota in the Gut. Diabetes Care 40, 54-62

90. Feng W, Ao H and Peng C (2018) Gut Microbiota, ShortChain Fatty Acids, and Herbal Medicines. Front Pharmacol 9, 1354

91. Parada Venegas D, De la Fuente MK, Landskron G et al (2019) Short Chain Fatty Acids (SCFAs)-Mediated Gut Epithelial and Immune Regulation and Its Relevance for Inflammatory Bowel Diseases. Front Immunol 10, 277

92. Waldman AD, Fritz JM and Lenardo MJ (2020) A guide to cancer immunotherapy: from $T$ cell basic science to clinical practice. Nat Rev Immunol 20, 1-18

93. Duan Q, Zhang H, Zheng J and Zhang L (2020) Turning Cold into Hot: Firing up the Tumor Microenvironment. Trends Cancer 6, 605-618

94. Bonaventura P, Shekarian T, Alcazer V et al (2019) Cold Tumors: A Therapeutic Challenge for Immunotherapy. Front Immunol 10, 168 